\title{
KONSEP DAN STRATEGI PENGEMBANGAN SMART REGIONAL (SMART CITY) DALAM MENGHADAPI GLOBALISASI VERSION 3.0 DENGAN MENGGUNAKAN METODE PDCA \& USEPDSA
}

\author{
Sasono Wibowo*, Indra Gamayanto \\ Fakultas Ilmu Komputer Departemen Sistem Informasi \\ Dian Nuswantoro University Imam Bonjol 207 \\ Korespondensi: sasono.wibowo@dsn.dinus.ac.id*, $\underline{\text { indra.gamayanto@dsn.dinus.ac.id }}$
}

\begin{abstract}
Smart city is a necessity and no longer a hope, but it has already happened, with the progress of information technology that is increasingly sophisticated and very fast, then changes occur in everyday human life, where humans have united themselves with technology. This journal is a development of two journals - The Future Of IS / IT Strategic Planning In WCC, Australia version 1.0 and the journal analysis of the Wollongong city council using $7 \mathrm{~s}$ of Galliers and Sutherland methods version 2.0. Furthermore, the focus of this journal - and at the same time the problem is that targets of high quality human resources have not been met; the application of technology and its use; and how the balance between HR and technology can be maintained very well. The results of this journal are the stages that can be carried out by each region in developing human resources and how the technology can help in regional development. It should be understood, that this journal has only reached level 3 (version 3.0), which means this journal is still a basic foundation with three stages, and this journal will be continued at the next level (the next version), gradually. Deepening of the supporting journals for this journal and observations and surveys are very important for the completion of information, therefore this journal will continue to be developed until the final stage
\end{abstract}

Keywords: Smart city, Smart regional, Human resources, Technology, Framework

\section{PENDAHULUAN}

Smart city merupakan sebuah dua kata penting yang dapat memberikan dampak besar terhadap sebuah perubahan kehidupan. Kita ketahui bahwa perkembangan teknologi informasi yang semakin pesat ini, akan dapat juga mengubah dan memiliki dampak signifikan terhadap perubahan pola kehidupan manusia sehari-hari dan tentunya hampir semua area mengalami perubahan yang belum ada di zaman dulu. Smart city merupakan salah satunya, di mana kehidupan berubah menjadi lebih efektif, efesien, praktis, serba cepat dan melalui kecepatan yang luar biasa, hal ini dapat disebut sebagai penyatuan antara manusia dan teknologi (human techonology).

Smart city adalah sebutan yang diberikan kepada kota yang menggabungkan teknologi informasi dan komunikasi (TIK) untuk meningkatkan kualitas dan kinerja layanan perkotaan seperti energi, transportasi dan utilitas untuk mengurangi konsumsi sumber daya, pemborosan, dan biaya keseluruhan. Tujuan utama smart city adalah untuk meningkatkan kualitas hidup warganya melalui teknologi pintar. Smart city adalah pengembangan kembali suatu daerah atau kota yang menggunakan teknologi informasi dan komunikasi (TIK) untuk meningkatkan kinerja dan kualitas layanan perkotaan seperti energi, konektivitas, transportasi, utilitas dan lain-lain. Smart city dikembangkan ketika teknologi 'pintar' digunakan untuk mengubah sifat dan ekonomi infrastruktur di sekitarnya. Tujuan smart city konsisten untuk mencakup smart living, smart people, smart environment, smart mobility, smart economy, smart governance, smart services, dan smart infrastructure. 
Artikel ini merupakan pengembangan dari dua jurnal yaitu: jurnal The Future of IS/IT Strategic Planning In WCC, Australia version 1.0 dan jurnal analysis of wollongong city council using 7s's Of galliers and sutherland methods version 2.0. Pada kedua jurnal ini, telah dihasilkan framework dalam mengelola sebuah kota dan dapat dikatakan ini sebagai awal untuk dikembangkan pada jurnal berikutnya, yang dinamakan e-regional version 3.0. Jurnal ini tidak berhenti sampai pada version 3.0 karena masih akan dikembangkan pada versi berikutnya. hal ini dapat digambarkan sebagai berikut:

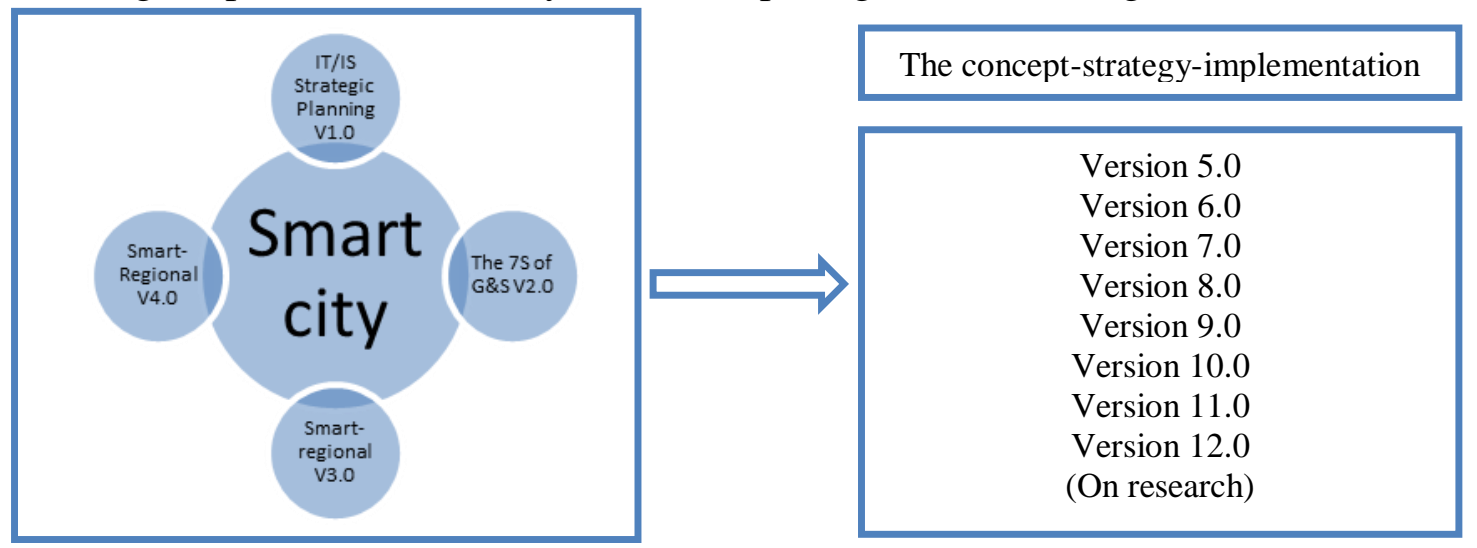

Gambar 1 Proses penelitian versi 1.0-12.0

Gambar 1 memperlihatkan sebuah proses penelitian dari tahap pertama sampai tahap dua belas. Penelitian ini baru mencapai tahap 3, di mana masih membutuhkan waktu untuk mencapai kesempurnaan.

Permasalahan utama di dalam penerapan smart city, pada jurnal ini akan berfokus pada pengembangan sumber daya manusia dan bagaimana teknologi tersebut dapat mengimbangi pengembangan SDM tersebut dan juga bagaimana SDM dapat mengimbangi kemajuan teknologi, dua hal ini satu kesatuan yang tidak boleh dipisahkan. Hasil dari jurnal ini adalah tahapan-tahapan dalam mengembangkan sumber daya manusia di daerah dan bagaimana teknologi sebagai faktor penunjang utama yang tidak boleh dipisahkan.

\section{METODE PENELITIAN}

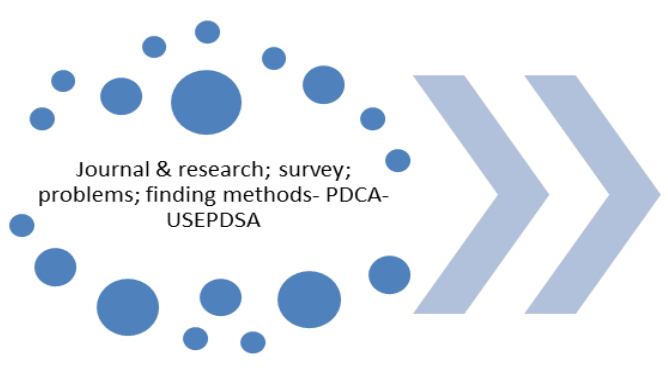

Analysis

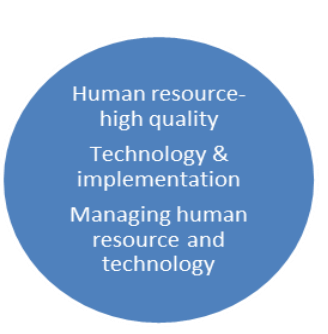

Result

Gambar 2 Proses penelitian

Pada gambar 1, merupakan sebuah proses jurnal ini, pertama-tama kami melakukan pengamatan dan analisis, melakukan analisis jurnal-jurnal lainnya untuk dapat menemukan literature yang tepat, dari analisis yang dilakukan, kami menemukan beberapa masalah dan kemudian menemukan metode yang tepat untuk menyelesaikan masalah tersebut, metode yang akan digunakan adalah PDCA dan USEPDSA. PDCA terdiri dari Plan (P) Merencanakan perubahan (pernyataan sasaran dan target; identifikasi proses-proses 
signifikan); Do (D)- Melaksanakan perubahan (Jika mungkin dalam skala kecil dahulu; identifikasi penyebab yang mungkin dari masalah kinerja; mengembangkan strategi pengumpulan data); Check (C)- Mengamati dampak perubahan (mengumpulkan data; evaluasi; menganalisis proses); Act (A) - Bertindak terhadap apa yang dipelajari (menentukan efektivitas; menetapkan perubahan proses). USEPDSA - Understand (U)merupakan improvement needs (memahami kebutuhan perbaikan); State (S)- the problems (menyatakan masalah yang ada); Evaluate (E)- the root causes (mengevaluasi akar masalah); Plan $(\mathrm{P})$ - do or implement the solutions (melaksanakan atau menerapkan rencana solusi terhadap masalah); Study (S)- the solutions results (mempelajari hasil hasil solusi terhadap masalah); Act (A)- standardize the solutions (bertindak untuk menstandarisasikan solusi terhadap masalah). Pertanyaan yang diajukan pada saat melakukan survey antara lain: (1) Apakah anda merasa bahwa fasilitas yang terdapat di daerah anda sudah memenuhi standar untuk membantu anda melakukan aktivitas seharihari atau bekerja?; (2) Apakah pendidikan di daerah anda sudah memadai dan memenuhi standar yang lebih dari cukup?; (3) Apakah perkembangan teknologi di daerah anda dapat membantu anda dalam melakukan aktivitas sehari-hari?; (4) bagaimana perkembangan sumber daya manusia di daerah anda?, survey ini diajukan kepada 20 orang, dan poin yang digunakan adalah poin 1-5.

Terakhir, jurnal ini menghasilkan bagaimana kita memiliki sumber daya manusia yang berkualitas tinggi; penerapan teknologi yang tepat dan bagaimana memanajemen sumber daya manusia.

\section{HASIL DAN PEMBAHASAN}

\subsection{Smart regional \& pengembangan sumber daya manusia (pendidikan)}

Pada bagian ini, terdapat beberapa hal penting, yang perlu dipahami terlebih dahulu, antara lain: (1) pendidikan merupakan hal yang sangat penting, dan untuk mengembangkan sebuah daerah, sebuah daerah harus memiliki pendidikan yang memiliki kualitas dan kompentensi yang tinggi; (2) pendidikan merupakan pusat dari kemajuan sebuah daerah, tanpa ketersediaan sumber daya manusia yang memadai, maka pembangunan sebuah daerah akan mengalami kendala yang serius; (3) perubahan pola pikir, budaya dan kebiasaan merupakan hal yang harus dikembangkan, karena tanpa perubahan ketiga hal tersebut, sebuah daerah akan mengalami beberapa kendala dalam menghadapi era globalisasi/pasar bebas/international market. oleh sebab itu, ketiga hal tersebut, harus menjadi dasar yang kuat terlebih dahulu sebelum melaju kepada pengembangan berikutnya.

Ketiga hal tersebut dapat diatasi dengan framework (kerangka) yang kami ciptakan dan dinamakan P3C (Pemetaan-Pengelolaan-Perubahan-Control). Kerangka ini merupakan hasil pemikiran kami dalam mengatasi permasalahan-permasalahan tersebut. Penerapan dari P3C adalah sebagai berikut:

3.1.1. Tahap 1: Pemetaan Pendidikan dan sumber daya manusia

1) Pemetaan pendidikan

Untuk mengembangkan sebuah daerah, pendidikan yang merupakan dasar dari kekuatan untuk menghadapi globalisasi, harus memiliki komptensi dan kualitas tinggi dari sisi kemampuan dan mentalitas. Sebagai contoh: kemampuan dalam berbahasa inggris, kompetensi dalam bidangbidang tertentu (pengeloaan keuangan; manajemen; proyek; teknologi dan 
sebagainya). Pemerintah dapat mulai dengan memetakan secara mendetail, di setiap daerah terdapat berapa banyak sekolah tingkat dasar, sekolah tingkat menengah, sekolah tingkat umum dan universitas yang memiliki kualitas tinggi, dan fokuskan pada mengembangkan kekuataan yang sudah ada. Hal ini dapat digambarkan sebagai berikut:

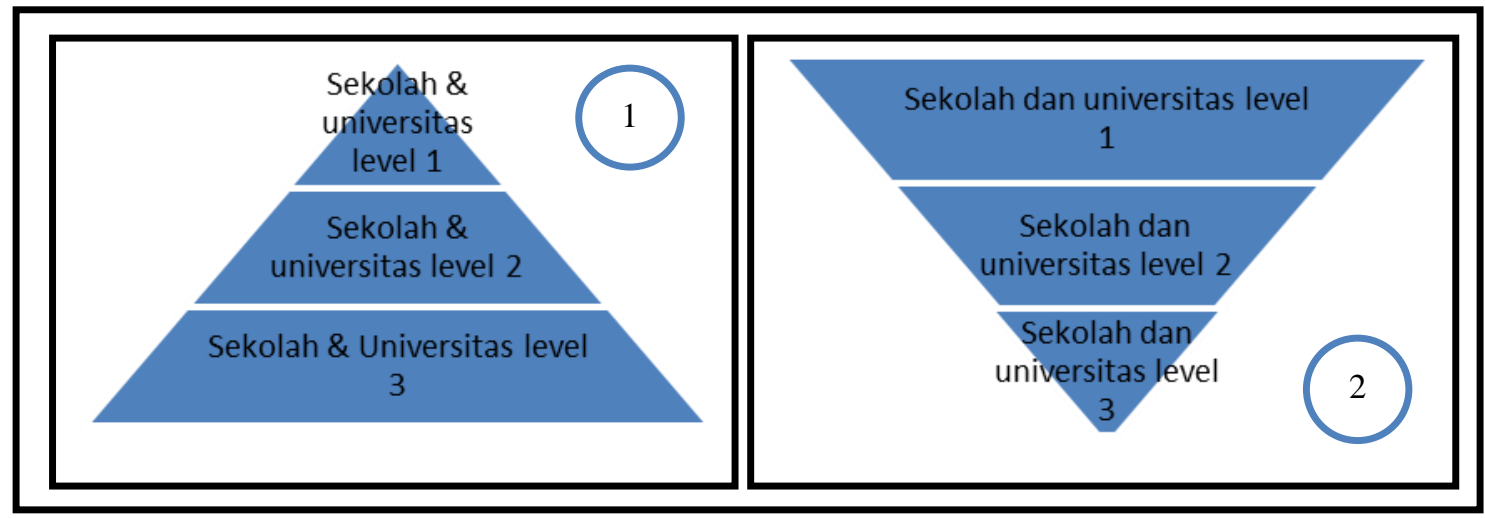

Gambar 3 Pemetaan pendidikan

Gambar 3, menjelaskan, dua piramida penting, piramida pertama, pada umumnya kita semua berfokus pada piramida satu, artinya kita cenderung berfokus pada hal-hal yang masih kurang dan berusaha untuk memperbaiki hal tersebut, hal ini akan mengakibatkan terbuangnya waktu, biaya dan sumber daya lainnya. Focus ini harus diubah seperti yang terdapat pada piramida kedua, yaitu yang kuat mengembangkan yang cukup dan yang cukup kuat mengembangkan yang lemah. Artinya: petakan terlebih dahulu, misal, 5 sekolah dasar terbaik di daerah tersebut, 5 sekolah tingkat menengah terbaik, 5 sekolah tingkat menengah umum dan 3 universitas terbaik. Pemerintah daerah berfokus untuk bekerjasama dan membantu agar apa yang sudah baik tersebut semakin kuat, pada saat yang bersamaan, petakan juga sekolah dan universitas yang masih membutuhkan pengembangan, dan terakhir petakan sekolah dan universitas yang memiliki masalah dan dalam pengawasan. Apa yang baik dari yang terbaik, yaitu level 3, harus dibagikan kepada manajemen level 2, sehingga level 2 dapat belajar memperbaiki apa yang masih kurang, dan setelah berhasil diterapkan di level 2, sekitar 70 persen, maka level 2 membagikannya kepada level 3. Tiga cara implementasi ini akan sangat menghembat anggaran, waktu dan sumber daya yang ada, karena pemerintah daerah berfokus pada apa yang sudah baik, dan apa yang sudah baik tersebut, harus membantu yang masih dalam taraf cukup, hal ini tentunya harus dimediasi oleh pemerintah daerah dan harus terdapat sebuah lembaga yang menengahi hal tersebut, ide dalam pikiran kami adalah "Rumah cerdas Indonesia", dimana di dalam konsep ini, terdapat data seluruh sekolah dan universitas secara mendetails, dan di klasifikasikan sesuai level yang ada. Klasifikasi ini dapat dijelaskan sebagai berikut: Level 1- merupakan sekolah dan universitas yang dimana terdiri dari dosen-dosen, guru dan murid-murid yang berprestasi, memiliki kemampuan bahasa inggris yang berkualitas tinggi, memiliki kemampuan lainnya yang menunjang, prestasi secara nasional dan international, 
memiliki manajemen yang baik dan mendapatkan penghargaan untuk hal tersebut. level 2, masih berkisar pada kata "cukup baik", tapi belum sempurna, artinya mungkin semua sisi sudah baik, tetapi kemampuan dalam bahasa inggris masih belum mencapai standarnya. Level 3- masih banyak hal yang kurang dari semua hal-hal yang sudah disebutkan di level 1 . Demikian konsep dalam pemetaan pendidikan di sebuah daerah.

2) Pemetaan sumber daya manusia

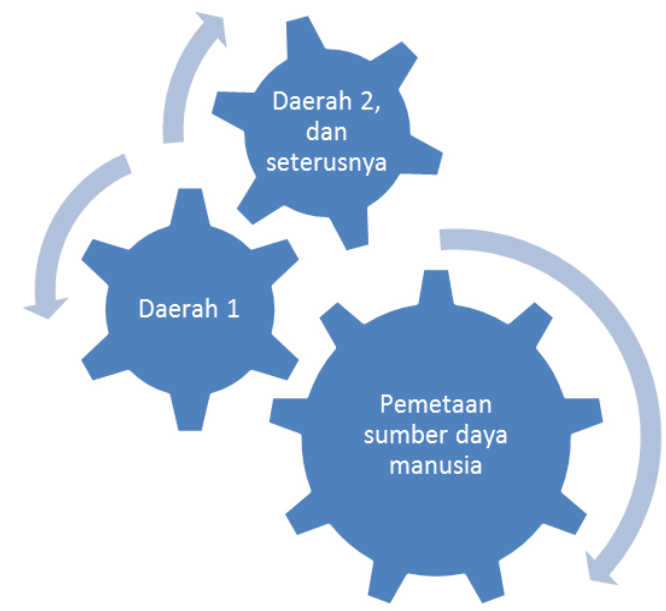

Gambar 4 Pemetaan sumber daya manusia di setiap daerah

Gambar 4, menjelaskan, bahwa pemerintah daerah harus dapat memetakan orang-orang yang memiliki kemampuan-kompetensi dan kualitas yang sangat tinggi. Sebagai contoh daerah A, memiliki jumlah penduduk 1 juta, maka daerah tersebut harus memiliki 12 orang yang dianggap memiliki kemampuan dalam hal: manajerial, teknologi, ahli-ahli dalam bidangnya, yang memiliki kompetensi dan kemampuan yang sudah diakui oleh nasional dan/atau international. Pertanyaannya adalah: mengapa hal ini dibutuhkan? Dan/atau mengapa hal ini harus diterapkan?, karena guna menghemat waktu, maka dibutuhkan dari orang-orang yang memiliki kapastias kemampuan dengan kualitas tinggi, tentunya ini harus mempertimbangkan dari sisi anggaran. Kemudian, jika orang-orang tersebut sudah tersedia, maka dapat dikumpulan di dalam "Rumah cerdas Indonesia". Standarisasi yang harus dimiliki oleh orang-orang tersebut antara lain: (1) Kemampuan berbahasa inggris dengan sangat baik; (2) Kemampuan dalam manajerial, teknologi informasi, organisasi; (3) Ahli budaya, dan lainnya, tentunya hal ini tidak menuntut bahwa satu orang memiliki seluruh kemampuan tersebut, tetapi jika 12 orang yang terdiri dari ahli teknologi informasi, ahli sistem informasi, ahli manajerial, dan lainlain, hal ini dapat saling melengkapi kekuatan dan kelemahan masingmasing. Ini yang disebut sebagai "Manajemen cerdas Indonesia".

3) Penerapan dengan metode PDCA \& USEPDSA

a. PDCA \& Sumber daya manusia-pendidikan

Plan (P) - identifikasi dan petakan sekolah; universitas yang sudah memiliki kompetensi dan standarisasi yang sangat baik secara nasional dan international. Identfikasi dan petakan orang-orang yang memiliki kemampuan dan kualitas tinggi, dengan standar 1 daerah 12 orang. 
Do (D) - Proses implementasi dimulai dari hal kecil terlebih dahulu, sebagai contoh sekolah A terbaik membantu sekolah B yang cukup baik dan sekolah B jika sudah mencapai standar 70 persen maka dapat membantu sekolah $\mathrm{C}, 1$ sekolah membantu 1 sekolah, single to single, jangan single to many. Universitas A membantu universitas B yang cukup baik dan universitas B jika sudah memenuhi standar, maka membantu universitas C. 12 sumber daya manusia di setiap daerah bertugas untuk memberikan usulah strategi cara mengembangangkan daerah, dan usulan-usulan tersebut jika memungkinkan harus dapat diterapkan secara berkesimambungan agar dapat menghasilkan pencapaian proyek yang mencapai tujuan

Check $(\mathrm{C})$ - pemerintah daerah harus melakukan pengawasan, dan mendata secara konsisten, dampak-dampak perubahan yang ada pada saat sekolah, universitas dan 12 sumber daya manusia ini melakukan tindakan dalam mengeksekusi. Hal ini sangat penting, karena dengan data perubahan yang sudah ada akan dapat dibuat strategi yang baru untuk dapat menyempurnakan apa yang sudah dilakukan

Act (A) - Di sini harus dapat ditentukan mana yang efektif dan efesien, dimana jika terjadi pemborosan anggaran yang sangat besar, harus dapat dipangkas, dan jika ada hal-hal yang sekiranya menghambat kemajuan sebuah proyek, maka hal tersebut harus dipangkas

b. USEPDSA \& Sumber daya manusia-pendidikan

Understand (U) - Pemerintah daerah harus dapat memahami kebutuhan utama dari setiap sekolah, universitas dan kebutuhan sumber daya manusia seperti apa khususnya di daerahnya-yang dibutuhkan untuk memajukan daerah tersebut. Kuncinya berada di pemetaan yang details dan tepat

State (S)- Identifikasi masalah pada setiap sekolah, universitas dan kebutuhan sumber daya manusia, sangat dibutuhkan, karena hal ini akan membantu pemerintah daerah untuk mengetahui akar permasalahan sesungguhnya

Evaluate (E) - evaluasi lebih mendalam lagi tentang masalah yang ada, dan melakukan breakdown penyelesaian masalah dengan target yang sudah ditetapkan

Plan (P) - do or implement the solutions (melaksanakan atau menerapkan rencana solusi terhadap masalah)

Study (S) - memberikan solusi pada setiap masalah untuk dapat bertindak dengan benar

Act (A) - jika hal itu sudah berhasil diterapkan, maka sangat perlu melakukan standarisasi

\subsubsection{Tahap 2: Smart regional \& Penerapan teknologi informasi}

\section{1) PDCA-USEPDSA Teknologi Informasi}

P3C (Pemetaan-Pengelolaan-Perubahan-Control), pada teknologi antara lain: (1) pemetaan daerah-daerah mana yang sudah memiliki kemajuan tingkat teknologi yang sangat baik; (2) pengelolaan pada daerahdaerah yang memiliki teknologi terbaik; (3) melakukan perubahan sedikit demi sedikit dengan memberikan dampak pada daerah lainnya; (4) mengendalikan dan pemeliharaan apa yang sudah baik. Hal ini dapat digambarkan sebagai berikut: 


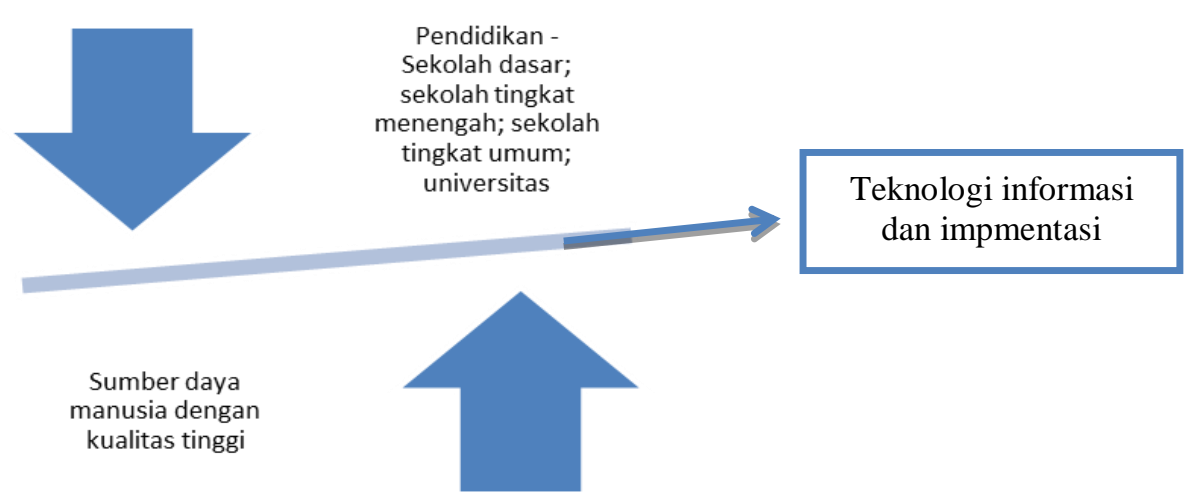

Gambar 5 Pendidikan-sumber daya manusia-teknologi informasi

Gambar 5, menjelaskan, bahwa teknologi informasi sebagai sarana utama dalam menunjang meningkatkan sumber daya manusia dan pendidikan. Hal ini terlihat pada gambar, bahwa kecepatan teknologi informasi akan dapat mempengaruhi banyak hal, mulai dari diperolehnya informasi, mengembangkan pengetahuan terbaru, inovasi dan perubahanperubahan dalam pengambilan keputusan.

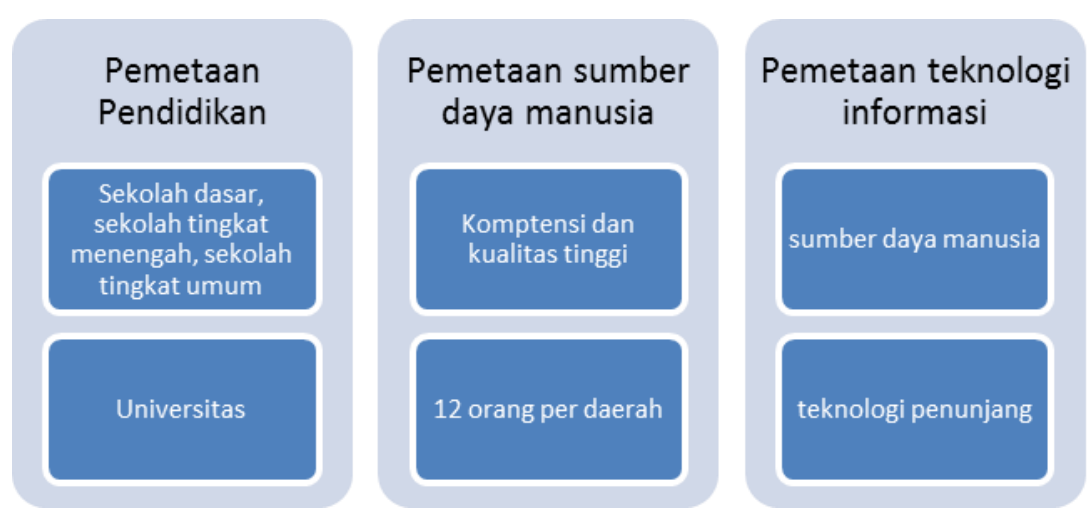

Gambar 6 Proses pemetaan tiga sisi dasar dari smart regional (bagian dari smart city)

Gambar 6, menjelaskan bahwa ketiga hal tersebut merupakan satu kesatuan yang tidak dapat dipisahkan satu sama lain. Pada gambar terlihat, bahwa pemetaan merupakan kunci utama dan dasar yang sangat penting dalam membangun smart regional, dengan pemetaan yang sangat details.

\subsubsection{Tahap 3: Framework smart regional (the fundamental)}

Framework (kerangka) smart city ini merupakan pengembangan dari jurnal sebelumnya, di mana, tentunya framework ini dirancang khusus untuk dapat menyesuaikan diri dengan budaya Indonesia, dan framework ini akan dijelaskan secara bertahap, dan fokus dari jurnal yang sekarang ini adalah pendidikan- sumber daya manusia dan teknologi informasi. framework ini dapat digambarkan sebagai berikut: 


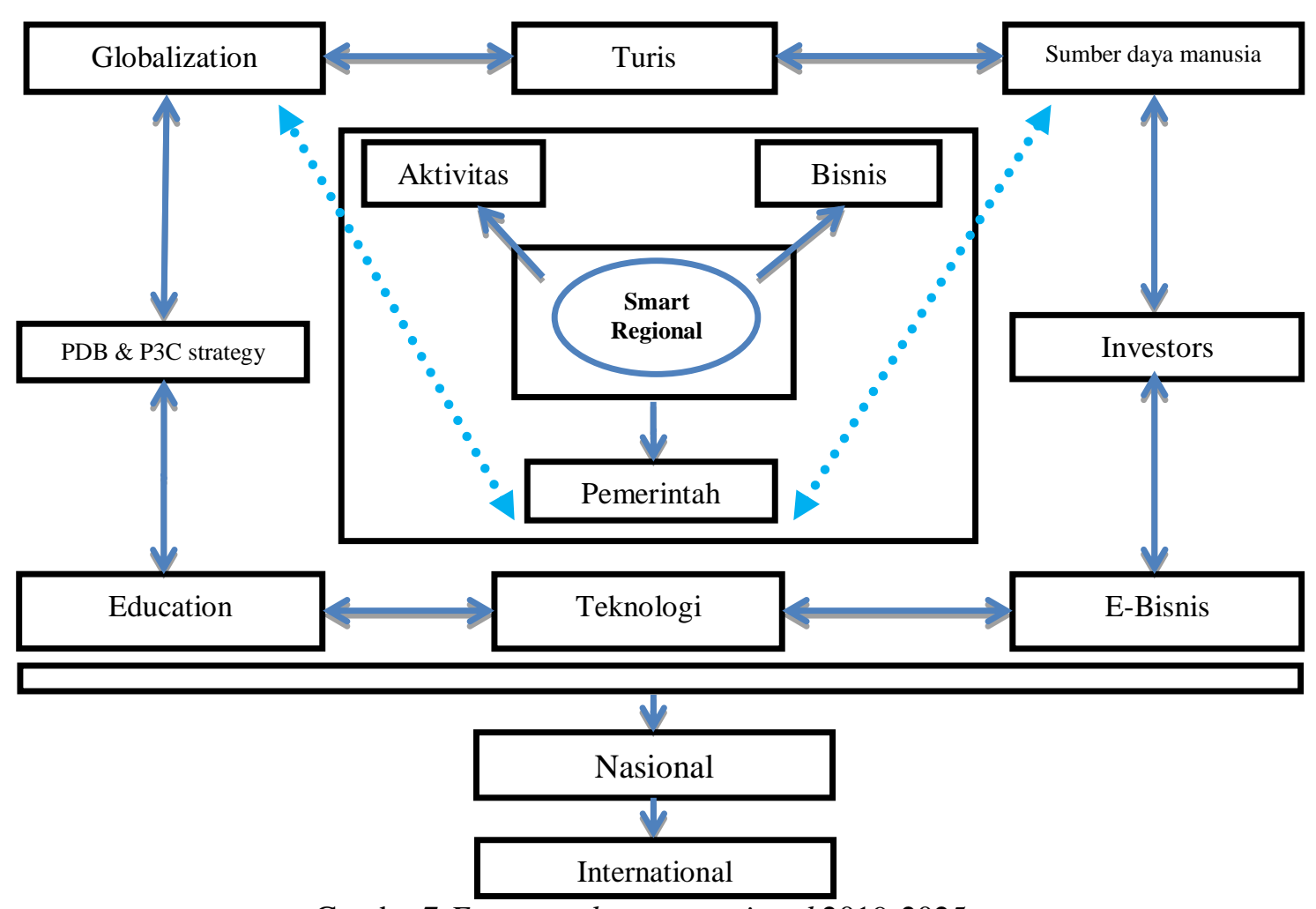

Gambar7 Framework smart regional 2019-2025

Gambar 7, merupakan framework baru yang dirancang untuk daerah, di mana framework ini dinamakan "framework smart regional 2019-2025". Dalam framework ini dihasilkan tiga tahap penting, antara lain: pada titik pusat "smart regional" yang terdiri dari aktivitas, bisnis, dan pemerintah. Pada tahap 2, terdiri dari sumber daya manusia, investors, e-bisnis, teknologi, education, $P D B \& P 3 C$ strategy, Globalisasi dan turis. Tahap akhir adalah tingkat nasional dan internasional. Tahapan ini akan dibahas dalam 12 versi. Bagian sumber daya manusia- education dan teknologi merupakan bagian pertama yang merupakan pembahasan dalam jurnal ini.

Pada gambar terlihat bahwa sumber daya manusia tidak bisa dipisahkan dengan teknologi dan teknologi juga tidak dapat dipisahkan dengan education dan globalization. Pada tahapan ini terdapat beberapa hal yang perlu dipahami, mengacu pada gambar 4, yang di mana terdapat tiga cara pemetaan secara details, jika hal ini dihubungkan dengan gambar 5, maka dihasilkan sebagai berikut:

Pertama, pendidikan membutuhkan bantuan teknologi. Artinya pendidikan dan teknologi harus seimbang. Jika dalam dunia pendidikan, tidak terdapat sumber daya manusia yang menunjang untuk menggunakan teknologi tersebut, maka hal tersebut akan menjadi masalah dalam sebuah proses, hal ini tentunya akan memboroskan biaya, karena teknologi yang ada, akan tidak digunakan, jika sumber daya manusia yang ada belum siap untuk menggunakan teknologi tersebut. perlu diingat, teknologi adalah penunjang tetapi sumber daya manusia adalah hal utama yang harus dimiliki terlebih dahulu.

Kedua, terdapat pemetaan terlebih dahulu, fungsinya dalah jika pemetaan tersebut berhasil dilakukan, maka, sebagai contoh: sekolah dan universitas yang sudah memiliki sumber daya manusia yang sangat baik tetapi belum memiliki 
teknologi penunjang, maka pemerintah dapat membantu untuk memberikan fasilitas tersebut. Hal itu akan memperkuat posisi sekolah dan universitas tersebut, yang selain sudah memiliki standarisasi yang sangat baik, memiliki teknologi penunjang untuk meningkatkan prestasi secara nasional dan international.

Ketiga, sekolah dan universitas yang sudah memiliki standarisasi baik dan ditunjang teknologi untuk mengembangkan kekuatannya, maka dapat membantu sekolah dan universitas lain yang masih dalam standar cukup, inilah yang disebut "manajemen cerdas rumah Indonesia" (sebuah konsep dan ide), di mana sistem ini berguna untuk memperkuat apa yang sudah kuat agar semakin baik dan kuat, yang kemudian membantu yang di bawahnya agar menjadi lebih baik dan seterusnya.

\section{SIMPULAN DAN SARAN}

\subsection{Simpulan}

Setelah melakukan analisis, maka penelitian konseptual ini menghasilkan beberapa kesimpulan, antara lain:

1) Smart regional version 3.0 ini merupakan pengembangan dari dua jurnal sebelumnya, yang menghasilkan ide untuk melakukan pemetaan di setiap daerah terutama di dunia pendidikan, seperti sekolah, universitas. Hal ini sangat penting karena akan menghasilkan sumber daya manusia yang berkualitas tinggi.

2) Setelah pemetaan ini dilakukan, maka analisis menggunakan metode PDCAUSEPDSA menghasilkan bagaimana sebuah daerah dapat menerapkan konsep, ide strategi smart regional version 3.0 ini.

3) Penelitian ini menghasilkan framework baru, yang disebut framework smart regional 2019-2025, yang di mana framework ini merupakan pengembangan dari version 1.0 dan 2.0 .

\subsection{Saran}

Penelitian ini akan terus dilanjutkan sampai pada version 120. Dimana focus dari penelitian ini untuk saat ini adalah: pendidikan, sumber daya manusia dan teknologi. Penelitian berikutnya adalah smart regional version 4.0, yang berfokus pada turis, investor dan beberapa hal penting lainnya.

\section{DAFTAR PUSTAKA}

A. Sinclair and P. White, "A Strategic role for HR: is it a competence issue?," Tax. Aust., vol. 50, no. 1, p. 16, 2015.

C. Sang Long, G. Chin Fei, U. Charles Amechi, and T. Owee Kowang, "The Relationship between HR Competencies and Organizational Performance in the Banking Sector in Nigeria," Int. J. Hum. Resour. Stud., vol. 8, no. 1, p. 217, 2018

D. Acemoglu and J. A. Robinson, "Rents and economic development: the perspective of Why Nations Fail," Public Choice, vol. 181, no. 1, pp. 13-28, 2019.

D. L. Deadrick and D. L. Stone, "Human resource management: Past, present, and future," Hum. Resour. Manag. Rev., vol. 24, no. 3, pp. 193-195, 2014.

F. A. Joshua, "Assessment of the Role and Functions of Human Resources Department in Small and Medium Scale Enterprise Companies in Ile - Ife , Osun," J. Hum. Resour. Manag., vol. 7, no. 2, pp. 32-40, 2019. 
H. Chourabi, J. R. Gil-garcia, T. A. Pardo, H. J. Scholl, S. Walker, and K. Nahon, "Understanding Smart Cities: An Integrative Framework," in Hawaii International Conference on System Sciences Understanding, 2012.

H. W. Lee, J. Pak, S. Kim, and L. Z. Li, "Effects of Human Resource Management Systems on Employee Proactivity and Group Innovation," J. Manage., vol. 45, no. 2, pp. 819-846, 2019.

H. Xu and X. Geng, "smart cities People-Centric Service Intelligence for Smart Cities," pp. 135$152,2019$.

I. Gamayanto, "Analysis of Wollongong City Council Using 7S' S of Galliers and Sutherland Methods," comptech J., no. 205, pp. 205-213, 2017.

I. Gamayanto, A. Rohmani, E. N. Florentina, and R. R. Sani, "The Future Of IS / IT Strategic Planning In WCC , Australia,” JOINS (Journal Inf. Syst., vol. 2, no. 2, pp. 167-178, 2017.

K. S. Kim and T. H. Shin, "Additive effects of performance- and commitment-oriented human resource management systems on organizational outcomes," Sustain., vol. 11, no. 6, 2019.

L. Zhang, X. Guo, Z. Lei, and M. K. Lim, "Social network analysis of sustainable human resource management from the employee training's perspective," Sustain., vol. 11, no. 2, 2019.

M. Armstrong and D. Brown, "Strategic Human Resource Management: Back to the future? A literature review Chartered Institute of Personnel and Development (CIPD)," 2019.

M. Mirzapour, S. S. Toutian, A. Mehrara, and S. Khorrampour, "The strategic role of human resource management in crisis management considering the mediating role of organizational culture," Int. J. Hum. Cap. Urban Manag., vol. 4, no. 1, pp. 43-50, 2019.

M. T. Latkovikj and M. B. Popovska, "Competency Framework for Human Resource," 2019.

M. Thite, "Smart cities : Implications of urban planning for human resource development Human Resource Development International Smart cities: implications of urban planning for human resource development," Hum. Resour. Dev. Int., vol. 14, no. November 2011, pp. 623-631, 2014.

N. W. Deriani and T. M. Kusuma, "The level of adoption of E-commerce by small-medium scale industries,” Int. J. Hum. Cap. Urban Manag., vol. 4, no. 2, pp. 0-5, 2019.

R. Berger, "The Smart City Breakaway," 2019.

R. Kitchin, P. Cardullo, and C. Di Feliciantonio, "Citizenship, Justice and the Right to the Smart City," 2018.

S. Joss et al., "The Smart City as Global Discourse : Storylines and Critical Junctures across 27 cities," J. Urban Technol., vol. 26, no. 1, pp. 3-34, 2018.

S. R. Torbatjoo, "Impact of human resources measures on organizational ambidexterity of smart city projects,” Int. J. Hum. Cap. Urban Manag., vol. 3, no. 4, pp. 325-334, 2018.

T. G. washington University, “GW Human Resources Strategic Plan 2017-2021,” 2017. 